\title{
Prevalence and predictors of respiratory symptoms and illnesses among farmers: a cross-sectional survey, Pakistan
}

\author{
Aneeta Khoso, ${ }^{1}$ Saba Wasim, ${ }^{2}$ and Saima Zainab ${ }^{1}$
}

${ }^{1}$ Liaquat National Hospital and Medical College, Karachi, Pakistan. ${ }^{2}$ Faculty of Biostatistics College of Science and Health Professions, King Saud Bin Abdulaziz University, Riyadh, Saudi Arabia. (Correspondence to: Aneeta Khoso: aneetakhoso@gmail.com)

\begin{abstract}
Background: Occupational exposures are one of the major causes of chronic respiratory symptoms and illnesses, where farming and its related activities make a significant contribution, especially in low- and middle-income countries such as Pakistan.
\end{abstract}

Aims: This study aimed to estimate burden of chronic respiratory symptoms and illnesses among farmers and to identify associated factors.

Methods: A translated version of American Thoracic Society Division of Lung Disease questionnaire (ATS-DLD-78A) was used among 381 farmers in Thatta District, Pakistan in 2011. Logistic regression analysis was used to assess the association between socio-demographic and occupational risk factors and respiratory illnesses.

Results: Chronic wheeze was reported in $65.9 \%$ of farmers exposed to pesticides compared to $34.1 \%$ of farmers not exposed ( $P$-value: 0.10$)$. Frequencies of other health events were almost similar among the two groups. On multivariable logistic regression analysis every 5 year increase in age of the farmer increased the risk of having respiratory illnesses by 18\% (Adjusted OR [AOR]: 1.18; 95\% CI: 1.03-1.35). Each 1000 Pakistani Rupees (PKR) increase in household income increased the risk of having respiratory illnesses by 10\% (AOR: 1.10; 95\% CI: 1.01-1.25).

Conclusions: Occupational Health and safety is a neglected area in many parts of the country especially when it comes to farmers. This study highlights the importance of factors other than pesticides impacting the respiratory health of the farmers, emphasizing on those who smoke tobacco.

Keywords: Farming, chronic respiratory symptoms and illnesses, pesticides, occupational health, Pakistan

Citation: Khoso A; Wasim S; Zainab S. Prevalence and predictors of respiratory symptoms and illnesses among farmers: a cross-sectional survey,

Pakistan. East Mediterr Health J. 2019;25(10):698-705. https://doi.org/10.26719/emhj.19.003

Received: 09/09/16; accepted: 26/07/18

Copyright (c) World Health Organization (WHO) 2019. Some rights reserved. This work is available under the CC BY-NC-SA 3.0 IGO license https:// creativecommons.org/licenses/by-nc-sa/3.0/igo

\section{Introduction}

Occupational factors make an important contribution to the global burden of disease, where work-related morbidity and mortality not only result in suffering for the worker and his family, but also adds to the overall cost to the society through lost productivity and increased use of medical and welfare services $(1,2)$. Subsequent to smoking, occupational risk factors are a major cause of chronic respiratory symptoms and illnesses, accounting for $13 \%$ of Chronic obstructive pulmonary disease (COPD), $11 \%$ of asthma and almost all cases of silicosis, asbestosis and pneumoconiosis globally (3). Respiratory illnesses have long been recognized in association with the occupation of farming (4).

Pesticides are widely used in most sectors of the agricultural production for effective pest management, improving the yield as well as quality of the produce. Worldwide, approximately 2.3 billion litres of pesticide are consumed annually (5), among which organophosphate (OP) and carbamate insecticides (34\%), dithiocarbamate fungicides $(18 \%)$ and phenoxyl herbicides $(12 \%)$ are the most commonly used $(4,6)$. Despite their effectiveness and extensive use, pesticides create serious health risks arising from the exposure of farmers (7). Pesticides are potential risk factors for the development of respiratory diseases among farmers along with a long list of other systems involved, through inhalation, dermal or oral exposure (8). The health impacts of pesticide inhalation through occupational exposure have been documented by several epidemiological studies, which have reported farmers at a higher risk of developing respiratory symptoms and illnesses (9-10). Pesticides, after reaching the lungs from the systemic circulation through inhalation and absorption, have an adverse effect on the lung tissues (11).

In Pakistan, agriculture accounts for more than $25 \%$ of output and $40 \%$ of employment (12). Cotton is a major crop in Pakistan following the cultivation of wheat. Compared to other crops, cotton occupies the largest area in the country. The largest export revenues are attributed to the cotton crop, whereby cotton and cotton related products contribute $10 \%$ to gross domestic product (GDP) and $55 \%$ to the foreign exchange earnings of the country. Increased crop production is accompanied by increased crop protection and the use of extensive amount of pesticides required for pest management (13).

Occupational use of pesticides may be involved with respiratory diseases along with other disorders of the endocrine system (14). A recent epidemiological study con- 
ducted in Niger, West Africa, demonstrated a significant relationship between respiratory manifestations and the agricultural characteristics of the living area, which included residence near the farm and type of insecticide used in the household (15). Insecticides, primarily cholinesterase-inhibiting compounds, may be associated with respiratory symptoms among agricultural workers $(16,17)$. Organophosphate insecticides have been found to have a causal link with occupational asthma in a population-based survey of Saskatchewan farmers, Canada (18). Carbamate insecticide use has been found to be linked with self-reported asthma and lower mean values on lung function tests among farmers (18).

Farmers in Pakistan mishandle pesticides owing to low awareness regarding the harms involved in pesticide use (19). This stems from the use of toxic chemicals that are banned or restricted in other countries, incorrect application techniques, poorly maintained or totally inappropriate spraying equipment and inadequate storage practices (19). Information on respiratory illness related to pesticide exposure is scant in Pakistan. Only one survey from the province of Sindh, reported a significant increase in respiratory disorders among farmers exposed to pesticides (19).

Since cotton crops require heavy amounts of pesticide use, this study was an attempt not only to estimate the burden of chronic respiratory symptoms and illnesses among the farmers involved in cotton crop cultivation, but also to identify the associated factors in order to recommend appropriate preventive measures among those farmers.

\section{Methods}

This was a cross-sectional survey conducted in Thatta, a District in the province of Sindh, Pakistan, during May 2011-June 2012. Pretesting of the study started in March 2011 and the data collection continued from April to July 2011. The period of data collection was kept in accordance with the spraying season of cotton crops to achieve uniform exposure of study participants. In addition, the data collection was confined to the cotton season since there are different requirements and frequencies of pesticide use, along with the types of pesticide required for specific crops following harvesting of cotton (20). This impacts exposure among farmers and their symptoms and illnesses accordingly.

\section{Selection of study participants}

Farms with cotton fields were identified in the mentioned area. Farmers were selected through a non-probability, purposive sampling technique due to lack of availability of listings of registered farms. Farms within the district of Thatta were approached and research was undertaken where owners and landlords gave permission. All male and female farm workers above 19 years of age working for at least 5 years were included. Exclusion criteria included farmers who refused to be part of the study, those who were involved in contractual / part-time jobs, and those who were prone to multiple exposures. Written, informed consent was obtained from all participants before inclusion in the study. This was done in the form of signatures or in the form of thumb impression from those who could not sign their names. The overall response rate was $95 \%$. The non-respondents were mostly those who were engaged in spraying and were not available for interview.

\section{Interviews}

A structured questionnaire obtained from the American Thoracic Society Division of Lung Disease questionnaire (ATS-DLD-78A) was used. Field testing of the final questionnaire was done before initiating the formal data collection. All the interviews were conducted in the local language "Sindhi". The ATS-DLD-78A is a standardized respiratory questionnaire and is useful for assessment of the burden of respiratory symptoms in an occupational setting. The questionnaire has been tested for its reliability for data collection with an overall Cronbach's alpha coefficient of $a=0.74$ (21). Thus, it is an effective tool for collecting data in a low- to middle-income country.

The data were collected by two local persons residing close to the farms. They were thoroughly briefed regarding the objectives of the study and were given a comprehensive training in which all details along with the questionnaire were explained to them. Special sessions were conducted on quality checks in data collection to ensure transparent collection of data. Quality of data was assessed through random checks by the principal Investigator. The structured questionnaire was used to obtain detailed information on sociodemographic characteristics and occupational factors. The questionnaire was piloted before being used in the study on a sample (10\% of the sample size) similar in socio-demographic characteristics and occupation, but residing at a different area, Makli, located 6 kilometres from Thatta. Some issues in the understanding of the questions were observed during the field testing, after which necessary changes were made and incorporated. History of chronic respiratory symptoms and illnesses was assessed through the questionnaire. The questions were reviewed by experts in the field for the content. Data were entered in Microsoft Excel software in the form of numeric codes assigned to different variables. The entered data were also verified by cross validating it with 10 randomly picked forms with the hard copies of the data sets.

\section{Operational definitions of the study outcomes (adopted from ATS guidelines)}

Chronic Cough was defined as cough occurring 4-6 times per day on most days of the week ( $\geq 5$ days) for at least 3 months of the year and for at least 2 consecutive years. Chronic Phlegm was classified as sputum expectoration twice a day on most days of the week ( $\geq 5$ days) for at least 3 months of the year and for at least 2 consecutive years. Chronic Wheeze can be defined as a whistling sound from the chest occasionally, apart from colds, on most days and nights. Chronic Bronchitis was defined 
as cough and sputum expectoration occurring for most days of the week ( $\geq 5$ days) for at least 3 months of the year and for at least 2 consecutive years. Asthma was classified as at least two or more attacks of shortness of breath with wheezing (whistling sound on expiration) in the past 2 months with normal breathing in between episodes of shortness of breath. A person was defined as an "Ever smoker" if the participant smoked more than 20 packets of cigarettes in a lifetime or more than one cigarette a day for 1 year. Ever smoker was further categorized into previous and current smokers. A person was defined as "Never smoker" if the participant had smoked less than 20 packs of cigarettes in a lifetime or less than one cigarette a day in 1 year.

\section{Sample size calculation}

Sample size was calculated using the 'sample size determination in health studies' software from the World Health Organization (WHO). Respiratory illnesses and their risk factors were considered in the sample size calculation. Sample size was calculated separately for cough, phlegm and asthma. However, the sample sizes calculated were not enough to power the study. Hence, the researchers included associated factors such as smoking and exposure to dust. At a confidence level of 95\% and bound on the error of $5 \%$, the largest sample size was 381 , taking the prevalence of smoking as $55 \%$. Since smoking status in Pakistani farmers was not available, the same data had to be used from a study conducted in a slightly different setting (22).

\section{Statistical analysis}

Data were analyzed using software STATA version 12. Descriptive statistics of socio-demographic variables were computed as frequency with percentages and mean with standard deviation or median with interquartile range (incase the data were not symmetrically distributed). Prevalence was estimated for the presence of chronic respiratory symptoms and illnesses by calculating the frequency and percentages of the occurrence of symptoms and illnesses among the farmers. Chi square test of significance was conducted in order to assess the difference in the frequency of respiratory symptoms and illness among the two groups of farmers, i.e., those who were exposed to pesticides vs. those who were not. The differences were then assessed for their significance by their $P$-values, with $P=0.05$ or less considered as significant.

The secondary objective of the study was to determine the relationship between work-related factors and respiratory illnesses, mainly chronic bronchitis and asthma. Univariate binary logistic regression analysis was conducted for the purpose. Unadjusted Odds ratios (ORs) and their 95\% confidence intervals were computed to assess associations between the independent (length of job years, type of work) and dependent variables (chronic bronchitis and asthma). All variables with $P<0.25$ and those having biological plausibility were included in the multivariable logistic regression model. A parsimonious and biologically meaningful model was developed that best explained risk factors independently associated with the outcome (chronic bronchitis and asthma). Correlations between various variables were checked, and an interaction was considered to be significant at $P<0.05$. Adjusted ORs with their confidence intervals were obtained for the different categories of independent variables.

\section{Ethical approval}

Ethical approval was obtained from Ethics Review Committee at the Aga Khan University, Karachi, Pakistan. Written informed consent was obtained from all participants in the form of signatures or thumb impressions. The data collector introduced himself/herself to the farmer and explained the objectives of the study. Pattern and time required for the interview was also conveyed to the respondent before the start of the interview.

The participants were assured that they would not be subject to any undue discomfort during the interview. They were informed that they would not receive any monetary incentive for participating in the study. They had been informed of their right to refuse to participate in the study at any time during the interview. The respondents were assured of the confidentiality of the information that they provided. All the interviewed workers were counseled about the harmful effects of the pesticide and the precautions required to be taken to minimize the exposure of pesticides.

\section{Results}

Table 1 shows the socio-demographic and occupational characteristics of the farmers. There were a total of 381 participants, 251 males (66.0\%) and 130 females (34.0\%). The overall response rate of participants was $95 \%$. The non-respondents were mostly those who were engaged in spraying and were not available for the interview. The mean age of the workers was 34.4 years $(S D=12.4$ years) and the majority of them were males (66\%). Most of them had never attended school (84.8\%), and $21.8 \%$ had smoked more than one cigarette a day for 1 year, of which $21.0 \%$ were current smokers. $54 \%$ of the farmers sprayed in the fields, mostly twice a day ( $96 \%$ ).

Table 2 shows the difference in chronic respiratory symptoms and illnesses between the two groups of farmers, i.e., those who sprayed pesticides (54\%) and those who did not (46\%). Frequency of chronic cough and phlegm along with asthma, chronic bronchitis and chronic wheeze were not particularly significant between the two groups of farmers.

Table 3 shows the Logistic Regression analysis on association of occupational and socio-demographic factors with respiratory illnesses, i.e., chronic bronchitis and asthma. On univariate analysis, age, number of hours the farmer works on farms, cigarette smoking and monthly household income were found to be significantly associated $(P<0.05)$ with having respiratory illnesses.

For multivariable logistic regression analysis, every 5 year increase in the age of the farmer increased the risk of 


\begin{tabular}{|c|c|}
\hline Variable & n \\
\hline Age (years) & Mean (SD): $34.4(12.4)$ \\
\hline \multicolumn{2}{|l|}{ Sex } \\
\hline Male & 251 \\
\hline Female & 130 \\
\hline \multicolumn{2}{|l|}{ Highest level of education } \\
\hline Never gone to school & 323 \\
\hline Primary & 42 \\
\hline Lower secondary & 03 \\
\hline Matriculation & 09 \\
\hline Intermediate & 04 \\
\hline Monthly Household income (PKR)* & $\begin{array}{l}\text { Median (IQR): } 5000.0 \\
\quad(3000.0-6000.0)\end{array}$ \\
\hline \multicolumn{2}{|l|}{ Ever smoked cigarette } \\
\hline Yes & 83 \\
\hline No & 298 \\
\hline \multicolumn{2}{|l|}{ Currently smoke cigarette } \\
\hline Yes & 80 \\
\hline No & 301 \\
\hline $\begin{array}{l}\text { Age when first started regular } \\
\text { cigarette smoking }\end{array}$ & $\begin{array}{l}\text { Median (IQR): } 21.5 \\
\quad(17.8-30.0)\end{array}$ \\
\hline Number of cigarettes per day & $\begin{array}{l}\text { Median (IQR): } 20 . \\
\text { o(10.0-20.0) }\end{array}$ \\
\hline \multicolumn{2}{|l|}{ Position/Job title } \\
\hline Landlord & 10 \\
\hline Farmer & 368 \\
\hline Tractor driver & 02 \\
\hline Labourer & 01 \\
\hline \multicolumn{2}{|l|}{ Number of times spray pesticide in a day } \\
\hline Once & 06 \\
\hline Twice & 197 \\
\hline Three or more & 02 \\
\hline Number of years working & $\begin{array}{c}\text { Median (IQR): } 20.0 \\
(15.0-30.0)\end{array}$ \\
\hline
\end{tabular}

having respiratory illnesses by $18 \%$ (Adjusted OR [AOR]:1.18; 95\% CI: 1.03-1.35). For each 1000 Pakistani rupees' increase in household income, the risk of having respiratory illnesses was increased by 10\% (AOR: 1.10; 95\% CI: 1.01-1.25). These two variables were statistically significant.

Farmers who ever smoked cigarette were $71 \%$ more likely to have respiratory illnesses compared to those who never smoked; these associations were, however, marginally significant (AOR: $1.71 ; 95 \%$ CI: 0.90-3.68). There was a significant interaction found between main exposure variables i.e. 'Number of hours the farmer works on the farm' (More than 7 hours and 7 hours or less) and 'Spraying pesticides' (Yes/No). Those farmers who did not spray pesticides but worked for more than 7 hours on the farm were $84 \%$ less likely to have respiratory illnesses (AOR 0.16; 95\% CI: 0.03 - 0.88) and the association was significant.
Table 2 Chronic respiratory symptoms and illness among farmers based on their exposure to pesticides in rural Sindh, Pakistan $(n=381)$

\begin{tabular}{lccc} 
Symptoms and illnesses & \multicolumn{2}{c}{ Pesticide use } & P-value \\
& Yes & No & \\
\hline Chronic cough & $51.4 \%$ & $48.6 \%$ & 0.71 \\
Chronic phlegm & $51.4 \%$ & $48.6 \%$ & 0.71 \\
Chronic wheeze & $65.9 \%$ & $34.1 \%$ & 0.10 \\
Chronic bronchitis & $55.9 \%$ & $44.1 \%$ & 0.84 \\
Asthma & $54.2 \%$ & $45.8 \%$ & 0.98 \\
\hline
\end{tabular}

\section{Discussion}

The main focus of this research was on determining the frequency of respiratory symptoms and illnesses and exploring occupational factors contributing towards the development of respiratory problems. Most of the findings closely match the results of the literature available on prevalence of respiratory symptoms and illnesses in different occupational settings where dust and pesticide exposure is common. A study conducted among farmers in Brazil showed $6.4 \%$ having chronic cough while $8.6 \%$ farmers having chronic phlegm (23). Asthma symptoms were reported in $12 \%$ farmers while $22 \%$ farmers reported having symptoms of chronic respiratory disease. The reason for the increased frequency of symptoms among our study participants could be the virtual absence of personal protective equipment during work in the farms. These activities included mixing, preparing, spraying and storage of pesticides. Personal protective measures were found to be observed by the farmers of Brazil, who reported less frequent respiratory symptoms compared to our population.

However, there are certain studies that have found a greater burden of respiratory problems among the farmers compared to the current study. A random sample of European crop farmers reported wheezing (14.9\%), asthma (3.3\%), nasal allergy (14.4\%), chronic phlegm (12.4\%), and symptoms at work $(22.0 \%)$ through a questionnaire based study (24). This effect could be due to the use of multiple crop farms employing a variety of pesticides, unlike our study using merely cotton farms with limited types of pesticides. A study conducted on Swiss farmers showed a similar prevalence with reporting of $16.0 \%$ for chronic obstructive pulmonary disease (COPD), 15.4\% for asthma symptoms, and $42.0 \%$ for reporting at least one workrelated symptom. These symptoms may also be attributed to the use of data from animal exposure in contrast to only restricting farm and pesticide exposure (25).

An important factor needed to be highlighted in this research is the virtual lack of awareness of the workers regarding the health impact of exposure to pesticides. Knowledge and practices of these workers were exceptionally poor. In this study none of the farmers reported use of any protective gear during work; only a few stated protecting their face with a piece of cloth while spraying pesticides, and thus the majority were exposed to chemicals for a long period of time without 
any protection. Similar practices have been observed in farmers in high income as well as low- and middleincome countries. Damalas et al. in a study conducted on farmers in Greece concluded that most farmers (49.3\%) showed potentially unsafe behaviour regarding the use of personal protective devices. They used hats and boots mostly, but showed low frequency of use of gloves, goggles, face mask, coveralls, and respirator (26).

The logistic regression model shows that as age increases, there is a significant rise in chronic respiratory illnesses. This finding is also biologically plausible since lung function is known to deteriorate with increasing age (27). None of the outcome variables were significantly associated with exposure of increasing number of hours at workplace or with spraying pesticides in the multivariate logistic regression model; however, for those who sprayed pesticides, association with working hours on the farm and respiratory illness differed from those who were not involved in spraying pesticides. Cigarette smoking, an established risk factor for chronic bronchitis and asthma proved by many studies (28-30) was marginally significant.

\section{Limitations}

The findings of this study are based on a subjective inquiry rather than being supported by objective measures. In this study, biological markers were not possible for several of the used pesticides. The estimated pesticide exposure based on the reporting of workers could present low accuracy or misclassification. To overcome the issue, other analytical methods such as biomarkers of internal dose could improve the chemical exposure accuracy. Due to limited resources and budget, spirometry could also not be performed to assess lung functions. The study being cross-sectional in design limits inferences on the causality of the associations between occupational exposures and respiratory symptoms and illnesses. As the symptoms were chronic and evaluation referred to an extended period of time, temporal ambiguity and/or recall biases may have occurred underestimating the associations. Due to limited scale of the study, there was no inclusion of a control group for comparison. However, comparisons have been made in the past to assess whether frequency of respiratory symptoms and illnesses were higher in such workers in comparison with general population. Although this study explains a number of factors associated with respiratory symptoms and illnesses, there are other factors that could not be studied due to the inclusion of a limited number of farms within the catchment area as a result of prohibitive travel expenses.

As information on the conditions studied was based on cumulative prevalence (lifetime prevalence), inaccurate recollections by farmers may have led to underestimation of exposure and effects, or reverse causality, thus limiting causality affirmations.

The odds ratio can be reduced by the healthy worker effect and should be considered as a minimum effect. This sampling effect has previously been observed in

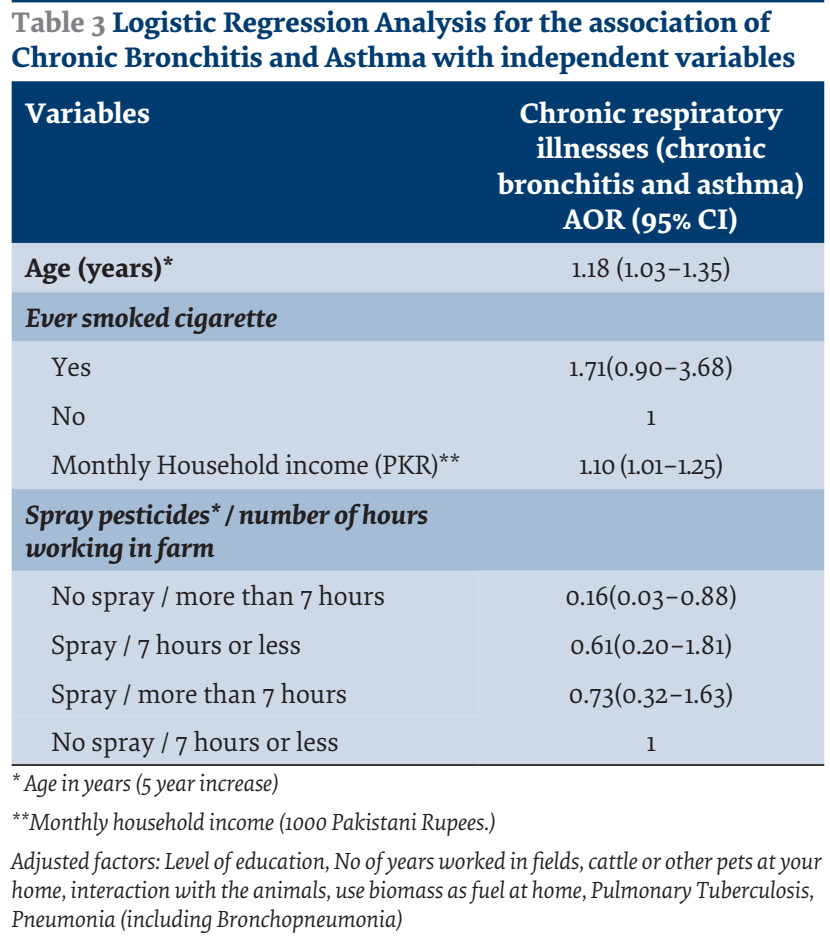

other studies (31-33) and tends to underestimate the differences between groups.

Characterization of exposure related to pesticides is difficult and unreliable in most low- and middle-income countries, owing to lack of resources. The best quantifiable measure of exposure is through biomarkers, in the form of blood samples. Owing to pesticide drift due to wind, an occupationally un-exposed population could be exposed and thus the exposure effect may be diluted (34). However, there have been studies conducted in the past that have assessed, with the help of a questionnaire, the impact of pesticides on exposed farmers and compared their symptoms with unexposed farmers (22). This study may not provide accurate quantifiable results of the exposure and its impact; however, given the lack of funds available, these figures do provide some insight into their current health and exposure status. This highlights the importance of further research with the help of biomarkers for a more quantitative measure of exposure.

\section{Conclusion}

Occupational Health and safety is a neglected area in many parts of Pakistan, especially when it comes to farmers. The evidence generated by this study needs to be further strengthened by conducting more objective research. Despite its limitations, this study highlights the importance of factors other than pesticides impacting the respiratory health of the farmers, emphasizing those who use tobacco products. A high frequency of respiratory symptoms and illnesses was observed in the farm workers, and a conducive work environment with protective interventions for safe practices is imperative for protecting the health of farmers. 


\section{Acknowledgments}

We thank Dr. Muhammad Masood Kadir, Dr. Zafar Fatmi, and Dr. Asaad Ahmad Nafees, Department of Community Health Sciences, Aga Khan University, Karachi, for their help and support in the study. We would also like to thank Dr. Wajiha Javed, and Mr. Muhamad Bashir Burfat, for their valuable input and support during different phases of the project. We greatly acknowledge all the farmers and the land owners who agreed to participate in the study.

Funding: International Training and Research in Environmental and Occupational Health in South Asia (ITREOH), National Institute of Health, University of Alabama at Birmingham, United States of America.

Competing interests: None declared.

\section{Prévalence et facteurs prédicteurs des symptômes et des maladies respiratoires chez les agriculteurs : enquête transversale au Pakistan}

\section{Résumé}

Contexte : Les expositions professionnelles comptent parmi les causes principales des symptômes et des maladies respiratoires chroniques, l'agriculture et ses activités connexes apportant une contribution significative, en particulier dans les pays à revenu faible et intermédiaire tels que le Pakistan.

Objectifs : Estimer le fardeau des symptômes et des maladies respiratoires chroniques chez les agriculteurs et identifier les facteurs associés.

Méthodes : En 2011, 381 agriculteurs, du district de Thatta (Pakistan), ont répondu à une version traduite du questionnaire établi par «l'American Thoracic Society Division of Lung Disease » (ATS - DLD - 78A). L'analyse de régression logistique a été utilisée pour évaluer l'association entre les facteurs de risque sociodémographiques et professionnels et les maladies respiratoires.

Résultats : Une respiration sifflante chronique a été signalée chez 65,9\% des agriculteurs exposés aux pesticides, par rapport à 34,1\% des agriculteurs non exposés (valeur $p=0,10$ ). La fréquence des autres événements de santé était presque la même dans les deux groupes. À l'analyse de régression logistique multivariables, chaque augmentation de cinq ans de l'âge de l'agriculteur est liée à l'augmentation du risque de contracter une maladie respiratoire de 18 \% (OR ajusté : 1,18 ; IC à 95 \%: 1,03 - 1,35). De même, chaque augmentation de 1000 roupies pakistanaises (PKR) du revenu du ménage accroît le risque de maladies respiratoires de $10 \%$ (OR ajusté : 1,10; IC $95 \%$ : 1,01 - 1,25).

Conclusions : La santé et la sécurité au travail sont négligées dans de nombreuses régions du pays, surtout lorsqu'il s'agit des agriculteurs. La présente étude souligne l'importance des facteurs autres que les pesticides ayant un impact sur la santé respiratoire des agriculteurs, l'accent étant mis sur ceux qui fument du tabac.

$$
\begin{aligned}
& \text { معدل انتشار الأعر اض والعلل التنفسية في أوساط المزارعين والعوامل المنبئة بها: مسح مستعرض في باكستان } \\
& \text { أنيتا خوسو، صبا وسيم، صايمة زينب } \\
& \text { الخلاصة } \\
& \text { الخلفية: يُعدّ التعرض لمخاطر مهنية أحد الأسباب الرئيسية للأعراض واضئ العلل التنفسية المزمنة، وتسهم الزراعة والأنشطة المرتبطة بها إسهاماً كبيراً في }
\end{aligned}
$$

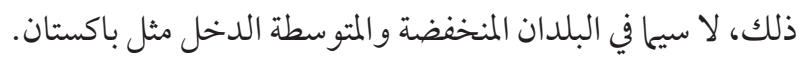

$$
\begin{aligned}
& \text { الأهداف: هدفت هذه الدراسة إلى تقدير عبء الأعراض والعلل التنفسية المزمنة في أوساط المزارعين، وتحديد العوامل ذات الصلة. }
\end{aligned}
$$

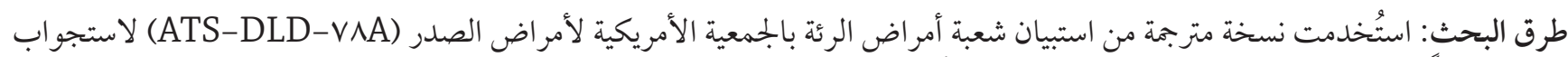

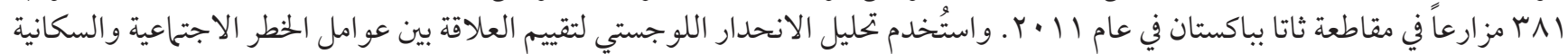

$$
\begin{aligned}
& \text { و المهنية والعلل التنفسية. }
\end{aligned}
$$

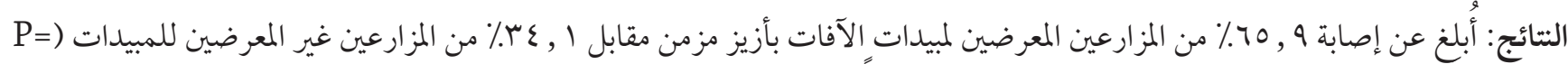

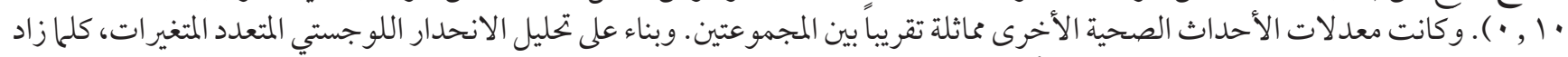

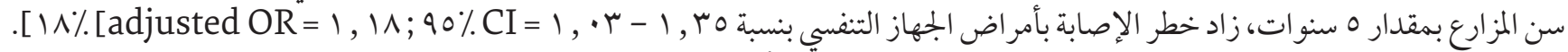

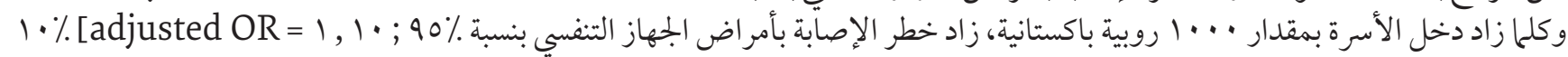

$$
\begin{aligned}
& \text {.[CI }=1, \cdot 1-1, \text { ro }
\end{aligned}
$$

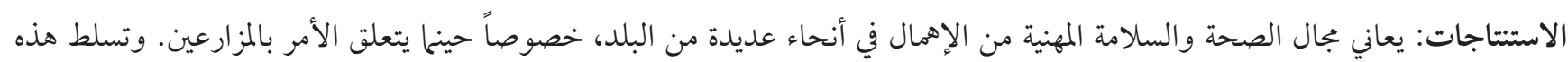

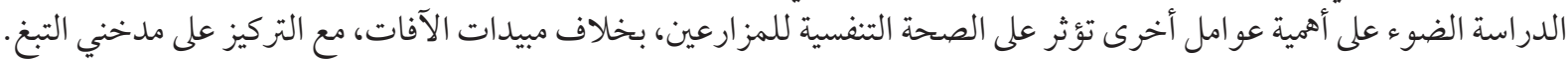




\section{References}

1. Biswas MJ, Koparkar AR, Joshi MP, Hajare ST, Kasturwar NB. A study of morbidity pattern among iron and steel workers from an industry in central India. Indian J Occup Environ Med. 2014; 18(3):122-28.

2. Kausar, A., \& Varghese, P. S. Occupational deaths at construction sites in Bangalore. IJBAR. 2012; 2(12):494-97.

3. Shaikh S, Nafees AA, Khetpal V, Jamali AA, Arain AM, Yousuf A. Respiratory symptoms and illnesses among brick kiln workers: a cross sectional study from rural districts of Pakistan BMC Public Health. 2012; 12:999.

4. Ye M, Beach J, Martin JW, Senthilselvan A. Occupational Pesticide Exposures and Respiratory Health. Int. J. Environ. Res. Public Health. 2013; 10(12):6442-71.

5. Grace communication foundation http://www.sustainabletable.org/263/pesticides, accessed 15 November 2013).

6. Food and Agriculture Organization of the United Nations (FAO)-Database on Pesticides Consumption (http://www.fao.org/waicent/FAOINFO/economic/pesticid.htm, accessed 15 November 2013).

7. Damalas CA, Eleftherohorinos IG. Pesticide Exposure, Safety Issues, and Risk Assessment Indicators. Int J Environ Res Public Health. 2011; 8(5):1402-19.

8. Anderson SE, Meade BJ. Potential Health Effects Associated with Dermal Exposure to Occupational Chemicals. Environ Health Insights. 2014; 8(Suppl 1):51-62.

9. Kimbell-Dunn M, Bradshaw L, Slater T, Erkinjuntti- Pekkanen R, Fishwick D, Pearce N. Asthma and allergy in New Zealand farmers. Am J Ind Med.1999; 35(1):51-7.

10. Hoppin JA, Umbach DM, London SJ, Alavanja MC, Sandler DP. Chemical predictors of wheeze among farmer pesticide applicators in the agricultural health study. Am J RespirCrit Care Med. 2002;165(5):683-9.

11. Fareed M, Pathak MK, Bihari V, Kamal R, Srivastava AK, Kesavachandran CN. Adverse Respiratory Health and Hematological Alterations among Agricultural Workers Occupationally Exposed to Organophosphate Pesticides: A Cross-Sectional Study in North India. Plos One. 2013; 8(7). https://doi.org/10.1371/journal.pone.0069755.

12. Zaki AR. Emerging Trends in International Business and Trade: Need for a Paradigm Shift for Pakistani Trade Bodies, 2014. IJFR; $5(1)$.

13. Rehman A, Jingdong L, Chandio AA, Hussain I, Wagan SA, Memon QUA. Economic perspectives of cotton crop in Pakistan: A time series analysis (1970-2015) (Part 1). Journal of the Saudi Society of Agricultural Sciences. 2016; https://doi.org/10.1016/j. jssas.2016.12.005.

14. SalamehP, Waked M, Baldi I, Brochard P, Saleh BA. Respiratory diseases and pesticide exposure: a case-control study in Lebanon. J Epidemiol Community Health. 2006; 60(3):256-61.

15. Mamane A, Tessier JF, Bouvier G, Salamon R, Lebailly P, Raherison C. Increase in the risk of respiratory disorders in adults and children related to crop-growing in Niger. J Environ Public Health. 2016; http://dx.doi.org/10.1155/2016/9848520.

16. Yemaneberhan H, Bekele Z, Venn A, Lewis S, Parry E, Britton J. Prevalence of wheeze and asthma and relation to atopy in urban and rural Ethiopia. Lancet. 1997; 350(9071):85-90.

17. Ohayo-Mitoko GJA, Kromhout H, Simwa JM, Boleij JSM, Heederik D. Self reported symptoms and inhibition of acetylcholinesterase activity among Kenyan agricultural workers. Occup Environ Med. 2000; 57(3):195-200. https://doi:10.1136/oem.57.3.195.

18. Senthilselvan A, McDuffie HH, Dosman JA. Association of asthma with use of pesticides: results of a cross-sectional survey of farmers. Am Rev Respir Dis. 1992; 146(4). https://doi.org/10.1164/ajrccm/146.4.884.

19. Tariq MI, Afzal S, Hussain I, Sultana N. Pesticides exposure in Pakistan: a review. Environ Int. 2007; 33(8):1107-22.

20. Sowing Period of Major Crops - Government of Sindh Agriculture Department (http://www.sindhagri.gov.pk/crop\%20calen/ showing\%20period.html accessed 13th September, 2017).

21. Nkosia V, Voyi K. Reliability of an adult respiratory symptom questionnaire in a community located near a mine dump in South Africa: pilot study. S Afr J Infect Dis. 2016; 31(3):103-5.

22. Beshwari M, Bener A, Ameen A, Al-Mehdi A, Ouda H, Pasha M. Pesticide-related health problems and diseases among farmers in the United Arab Emirates. Intern J Environmental Health Res, 1999; 9(3):213-21.

23. Faria NM, Facchinib LA, Fassab AG, Tomasic E. Pesticides and respiratory symptoms among farmers. Rev SaudePublica. 2005; 39(6):973-81.

24. Monsó E, Magarolas R, Radon K, Danuser B, Iversen M, Weber C et al. Respiratory symptoms of obstructive lung disease in European crop farmers. Am J RespirCrit Care Med. 2000; 162(4 Pt 1):1246-50.

25. Danuser B, Weber C, Künzli N, Schindler C, Nowak D. Respiratory symptoms in Swiss farmers: an epidemiological study of risk factors. Am J Ind Med. 2001; 39(4):410-8.

26. Damalas CA, Abdollahzadeh G. Farmers' use of personal protective equipment during handling of plant protection products: Determinants of implementation. Sci Total Environ. 2016; 571:730-6. https://doi: 10.1016/j.scitotenv.2016.07.042.

27. Sharma G, Goodwin J. Effect of aging on respiratory system physiology and immunology. ClinInterv Aging. $2006(3) ; 1: 253-60$.

28. Torres-Duque C, Maldonado D, Pérez-Padilla R, Ezzati M, Viegi G. Biomass Fuels and Respiratory Diseases A Review of the Evidence. Proc Am Thorac Soc. 2008; 5(5):577-90. 
29. Forey BA, Thornton AJ, Lee PN. Systematic review with meta-analysis of the epidemiological evidence relating smoking to COPD, chronic bronchitis and emphysema. BMC Pulm Med. 2011; 11:36.

30. Siracusa A, Marabini A, Folleti A, Moscato G. Smoking and occupational asthma. ClinExp Allergy. 2006; 36(5):577-84.

31. Hoppin JA, Umbach DM, London SJ, Alavanja MC, Sandler DP. Animal production and wheeze in the Agricultural Health Study: interactions with atopy, asthma, and smoking. Occup Environ Med. 2003; 60(8).

32. Kimbell-Dunn M, Bradshaw L, Slater T, Erkinjuntti- Pekkanen R, Fishwick D, Pearce N. Asthma and allergy in New Zealand farmers. Am J Ind Med.1999; 35(1):51-7.

33. Xu X, Niu T, Christiani DC, Weiss ST, Chen C, Zhou Y, et al. Occupational and environmental risk factors for asthma in rural communities in China. Int J Occup Environ Health. 1996; 2(3):172-6.

34. Mandel JS, Alexander BH, Baker BA, Acquavella JF, Chapman P, Honeycutt R. Biomonitoring for farm families in the farm family exposure study. Scand J Work Environ Health. 2005; 31 Suppl 1:98-104. 